DOI: $10.47456 / k r k r . v 1 i 4.31497$

\title{
Educação do campo e resolução de problemas em uma escola comunitária rural
}

\author{
Field education and problem solving in a rural community school \\ Cidimar Andreatta \\ Norma Suely Gomes Allevato
}

Resumo: O presente artigo propõe discutir aspectos da metodologia Resolução de Problemas como possibilidade para o ensino de Matemática em uma Escola Comunitária Rural que adota a Educação do Campo como modalidade de ensino da Educação Básica. De acordo com a legislação oficial brasileira (BRASIL, 2002), a Educação do Campo é considerada como modalidade de ensino da Educação Básica, tendo em vista sua vinculação às questões inerentes à sua realidade, articulando-se a temporalidade e saberes próprios dos estudantes. Este trabalho, de natureza bibliográfica e aplicada faz parte de uma pesquisa maior de doutoramento (ANDREATTA, 2020), composto de uma seção introdutória em que caracterizaremos a modalidade de Ensino Educação do Campo e a metodologia da Resolução de Problemas - $\mathrm{RP}^{1}$ para a aprendizagem de conteúdos e conceitos matemáticos. Em seguida, relataremos discussões teóricas acerca da Educação do Campo e da RP em contextos históricos e de aprendizagem, seguidas de uma prática pedagógica envolvendo a RP em turma de $5^{\circ}$ ano do Ensino Fundamental de uma Escola Municipal Comunitária Rural - EMCOR, localizada no interior do estado do Espírito Santo. Por fim, exporemos as considerações finais e as referências. Os resultados da pesquisa demonstram que a aprendizagem dos estudantes ocorreu em um ambiente de diálogo e participação coletiva, principalmente quando os estudantes tiveram a oportunidade de discutir as resoluções do problema.

Palavras-Chave: Educação do Campo; Aprendizagem Matemática; Resolução de Problemas.

Abstract: This article proposes to discuss aspects of the Problem Solving methodology as a possibility for teaching Mathematics in a Rural Community School that adopts Rural Education as a Basic Education teaching modality. According to the official Brazilian legislation (BRAZIL, 2002), Education in the Countryside is considered as a teaching modality of Basic Education, in view of its connection to issues inherent to its reality, articulating the temporality and knowledge of the students. This work, of bibliographic and applied nature, is part of a larger doctoral research (ANDREATTA, 2020), composed of an introductory section in which we will characterize the modality of Teaching Rural Education and the methodology of Problem Solving - PR for the learning of mathematical concepts and contents. Then, we will report theoretical discussions about Rural Education and PR in historical and learning contexts, followed by a pedagogical practice involving PR in the 5th grade of Elementary School of a Rural Community School EMCOR, located in the interior of the state of the Holy Spirit. Finally, we will present the final considerations and references. The results of the research demonstrate that the

\footnotetext{
${ }^{1}$ No presente artigo utilizaremos a sigla RP para designar Resolução de Problemas.
} 
students' learning took place in an environment of dialogue and collective participation, especially when students had the opportunity to discuss the resolutions of the problem.

Keywords: Rural Education; Mathematics Learning; Problem Solving.

\section{Introdução}

O foco central do presente artigo é apresentar discussões históricas e teóricas acerca da metodologia da Resolução de Problemas (RP) em articulação a Educação do Campo, assim como uma prática pedagógica envolvendo o trabalho com essa metodologia para a aprendizagem de conteúdos e conceitos matemáticos em uma Escola Municipal Comunitária Rural.

A Educação do Campo como modalidade de ensino da Educação Básica, está amparada pelas Diretrizes Operacionais para a Educação Básica nas Escolas do Campo (BRASIL, 2002), ratificada pelas Diretrizes Curriculares Nacionais Gerais para a Educação Básica (BRASIL, 2010), assim como outras legislações que discutiremos mais adiante na seção destinada a essa modalidade de ensino.

De acordo com tais diretrizes, o poder público precisa garantir a universalização do acesso da população do campo à Educação Básica e à Educação Profissional Técnica de Nível Médio, considerando a importância da educação escolar para o exercício da cidadania plena e para o desenvolvimento de um país ancorado na justiça social, na solidariedade e no diálogo entre todos, independente de sua inserção em áreas urbanas ou rurais.

Considerando as características, a cultura e o modo de vida dos estudantes da Educação do Campo, é que entendemos a possibilidade do trabalho pedagógico com a metodologia RP nessa modalidade de ensino da Educação Básica. A RP, como metodologia de ensino, está prevista nos Parâmetros Curriculares Nacionais - PCN (BRASIL, 1997, 1998) e na Base Nacional Comum Curricular - BNCC (BRASIL, 2017).

A proposta de discussão neste texto envolve a perspectiva da RP como metodologia de ensino, ou seja, como um recurso em favor da aprendizagem de conteúdos e conceitos matemáticos na modalidade de ensino - Educação do Campo. 


\section{Educação do Campo: contexto histórico e legislação oficial}

De acordo com Andreatta (2013) a Educação do Campo surge no Brasil em um movimento de tentar romper com uma formação tecnicista voltada para as demandas do processo de industrialização, no qual o homem do campo e sua família não eram atendidos sob oferta de educação que contemplasse o desenvolvimento social e educacional.

A Educação do Campo surge então em um contexto de debates/embates, tentando instituir-se como um novo paradigma educacional, com a perspectiva de adotar um conceito mais amplo sobre educação nas dimensões familiar, afetiva e de trabalho, buscando a constituição do protagonismo dos sujeitos do campo em suas organizações sociais, a fim de complementar e potencializar o saber.

A realização da I e II Conferência Nacional por uma Educação Básica no Campo, ocorridas em Luziânia - GO, nos anos de1998 e 2004, respectivamente, articularam uma agenda de reivindicações, baseadas nos movimentos de Educação Popular de Paulo Freire, na tentativa de combater o descaso do Estado para com as questões da educação da população rural (ANDREATTA, 2013).

Participaram dessas conferências diversos Movimentos Sociais, Sindicais, Organizações Sociais de Trabalhadores e Trabalhadoras do Campo e da Educação; das Universidades, Organizações Não Governamentais e Órgãos de Gestão Pública com atuação vinculada à educação e ao campo que reafirmaram a luta social por um campo visto como espaço de vida e por políticas públicas específicas para sua população.

As reivindicações, mobilizações e conferências contribuíram para a conquista de diretrizes e leis voltadas para a política de Educação Básica adequada para o campo. Podemos citar a Lei de Diretrizes e Bases da Educação Nacional (BRASIL, 1996) que destaca em seu artigo 28 que os sistemas de ensino na oferta da Educação Básica para a população rural poderão promover adaptações necessárias à sua adequação às peculiaridades da vida rural e de cada região por meio de conteúdos curriculares e metodologias adequadas as necessidades e interesses dos estudantes do campo, bem como adequação do 
calendário escolar às fases do ciclo agrícola e às condições climáticas e adequação à natureza do trabalho na zona rural.

Citamos também as Diretrizes Operacionais para a Educação Básica nas Escolas do Campo (BRASIL, 2002), assim como o Parecer do Conselho Nacional de Educação n. 1 de 01 de fevereiro de 2006 (BRASIL, 2006), que estabelece dias letivos para a aplicação da Pedagogia da Alternância nos Centros Familiares de Formação em Alternância. Em um contexto histórico mais atual tivemos a homologação das Diretrizes Curriculares Nacionais Gerais para a Educação Básica (BRASIL, 2010) que caracterizou a Educação do Campo como uma modalidade de ensino da Educação Básica.

A referida Diretriz da Educação Básica (BRASIL, 2010) destaca que deverão ser acolhidas formas de organização e metodologias pertinentes à realidade do campo como a Pedagogia da Terra, no qual se busca um trabalho fundamentado na sustentabilidade, para assegurar a preservação da vida das futuras gerações, e a Pedagogia da Alternância $^{2}$, na qual o estudante participa, concomitantemente e alternadamente de ambientes de aprendizagem na escola e no meio familiar/comunitária, supondo parceria educativa, em que ambas as partes são corresponsáveis pela formação e aprendizagem do estudante.

Na Pedagogia da Alternância, a organização das atividades didáticopedagógica prevê o trabalho e a realidade do estudante como elementos centrais para as aprendizagens, funcionando como uma pedagogia preocupada com a relação entre a vida prática laboral e a escola, numa relação dialética: prática teoria - prática. Nessa relação o diálogo é fundamental, uma vez que seus elementos constitutivos são ação e reflexão, podendo ser agentes de transformação da realidade e da constituição da autonomia do sujeito (FREIRE, 1981).

2 De acordo com Andreatta (2013) a Pedagogia da Alternância foi introduzida no Brasil, no final da década de 60, no interior do estado do Espírito Santo, recebendo forte influência das experiências francesas e italianas. O estado do Espírito Santo concentra o maior número e a maior diversidade de instituições pedagógicas em alternância. São diversas as denominações dessas escolas consideradas como Centros Familiares de Formação em Alternância que podem ser Escolas Famílias Agrícolas, Escolas Famílias Autônomas, Escolas Comunitárias Rurais, entre outras. 
Nesse contexto de relação entre comunicação e aprendizagem é que vemos possibilidades de conexão entre Educação do Campo e a Resolução de Problemas ao perceber a importância do diálogo e da reflexão nas aulas de Matemática. A PA tem o diálogo como um dos elementos centrais na formação do sujeito, o que, em geral, não percebemos nos ambientes tradicionais de ensino que não adotam a PA.

\section{Educação do Campo e Pedagogia da Alternância no contexto do município de Colatina e na escola participante da pesquisa}

A Educação do Campo, como modalidade de ensino da Educação Básica, iniciou-se oficialmente no município de Colatina com a aprovação e a promulgação da Lei Municipal n. ${ }^{\circ}$ 5.864, de 10 de julho de 2012 (COLATINA, 2012), após um longo processo de planejamento, debates e discussões entre poder público e as comunidades rurais. A referida lei destaca que essa modalidade de ensino será desenvolvida, preferencialmente, pela Pedagogia da Alternância - PA.

Esse processo de planejamento e discussões foi fundamental para a implantação da Educação do Campo no município, que emergiu da necessidade e da vontade das comunidades rurais de ter uma educação pública que pudesse atender às especificidades da região.

Após muitas discussões e abertura por parte do poder público municipal foi que, no ano letivo de 2011, a escola participante da pesquisa, passou pelo processo de transformação de escola regular para Escola Municipal Comunitária Rural - EMCOR "Pe. Fulgêncio do Menino Jesus", por meio da Lei Municipal n. ${ }^{\circ}$ 5.734, de 29 de junho de 2011 (COLATINA, 2011). Nesse mesmo ano ocorreu a transformação da Escola Pluridocente Municipal "São João Pequeno" para Escola Comunitária Rural e, mais tarde, no ano letivo de 2013, mais duas escolas municipais passaram a se organizar com a metodologia da PA.

Inicialmente a escola participante da pesquisa passou a se organizar metodologicamente com a Pedagogia da Alternância somente nos Anos Finais do Ensino Fundamental. A expansão para os Anos Iniciais e a Educação Infantil foi ocorrendo de forma gradativa, com a utilização e aperfeiçoamento dos intrumentos da PA. 
Mais recentemente, no ano letivo de 2016, houve a transformação de mais uma escola unidocente municipal para EMCOR, localizada na região leste do município. Ela passou a denominar-se EMCOR "Fazenda Pinotti". Com a expansão de várias escolas municipais como modalidade de ensino da Educação do Campo, foi necessário regulamentar a Lei Municipal n. ${ }^{\circ}$ 5.864, de 2012, com especificações e mais detalhes quanto à organização e ao funcionamento das escolas em relação à adoção da Pedagogia da Alternância.

Nesse sentido, a Lei Municipal n. ${ }^{\circ}$ 6.362, de 03 de novembro de 2016 (COLATINA, 2016), passou a regulamentar a lei n. ${ }^{\circ} 5.864$, de 2012. Nessa nova lei fica assegurada, às escolas municipais que se constituem como um Centro Familiar de Formação por Alternância - CEFFA, a utilização dos intrumentos pedagógicos da PA, fundamentais para o desenvolvimento e a formação dos estudantes, levando em consideração a dinâmica socioeconômica da comunidade local das escolas e seus entornos.

Atualmente a escola - EMCOR "Padre Fulgêncio do Menino Jesus" atende estudantes desde a Educação Infantil até os Anos Finais do Ensino Fundamental, fazendo o uso de alguns intrumentos pedagógicos específicos dessa metodologia. A seguir discutiremos brevemente alguns instrumentos pedagógicos que vêm sendo utilizados pela escola.

A EMCOR "Pe Fulgêncio do Menino Jesus" tem priorizado, para o desenvolvimento de suas atividades, instrumentos pedagógicos como Plano de Estudo, Caderno da Realidade, Caderno de Acompanhamento, Visitas e Viagens de Estudos e Avaliação de Habilidade e Convivência.

Gimonet (2007) destaca que, se os instrumentos pedagógicos não explorarem o contexto de inserção das escolas com projetos educativos consolidados, pode ocorrer uma justaposição de atividades escolares. Os instrumentos pedagógicos da PA possibilitam a integração entre teoria e prática na práxis educativa das escolas, sendo o Plano de Estudo um deles.

De acordo com Telau, (2012) o Plano de Estudo é considerado um instrumento guia da Pedagogia da Alternância, que possibilita a construção e a efetivação entre teoria e prática. $O$ plano orienta que todas as atividades desenvolvidas pelas escolas sejam pensadas e consolidadas de forma 
colaborativa e argumentativa. A essência do Plano de Estudo é estudar os fenômenos a partir de uma manifestação objetiva/concreta e problematizá-los com diálogos e reflexões, em consonância com a teoria e os conhecimentos científicos. Esse movimento pode proporcionar as condições para desenvolver novos saberes e práticas.

Ademais, Andreatta (2013) ressalta que ele é um meio didáticopedagógico elaborado pelos professores/monitores da unidade de ensino e que ajuda a conduzir a aprendizagem, pois parte da necessidade do contexto local, levando os estudantes a descobrirem práticas e experiências utilizadas por seus familiares e pela comunidade.

Outro instrumento pedagógico da PA é o Caderno da Realidade, considerado por Gimonet (2007, p. 32) como um "livro de vida, rico em si mesmo de informações, análises e aprendizagens variadas". O caderno articula-se aos livros acadêmicos ou didáticos para enriquecê-lo e para "construir o grande livro dos saberes a serem aperfeiçoados e das aprendizagens a serem feitas no presente de um percurso para o futuro" (p. 32). Ele permite sistematizações e reflexões provocadas pelo Plano de Estudo, com registros realizados pelos estudantes acerca das reflexões e das experiências educativas acontecidas durante o processo de formação dos estudantes, que pode ter sido na escola, na família ou na comunidade.

Por outro lado, o Caderno de Acompanhamento é um meio de comunicação e ligação entre a família do estudante e a unidade escolar. Nele são registradas, também pelos estudantes, as informações das atividades realizadas no meio familiar ou comunitário com o acompanhamento da família que atesta as atividades. Ele também leva as vivências ocorridas no ambiente escolar, atestado pelos professores e monitores (FREITAS, 2015).

A Avaliação de Habilidade e Convivência, também conhecida como Colocação em Comum, ocorre, geralmente, após a realização das atividades desenvolvidas pelos estudantes no meio familiar ou comunitário. Nesse momento, os estudantes socializam e sistematizam, na unidade escolar, os dados e informações colhidos na pesquisa realizada no âmbito da família ou da comunidade, de acordo com o Plano de Estudo, tendo a oportunidade de 
conhecer a realidade dos colegas dentro de um determinado tema, assim como os problemas, as potencialidades e os aspectos que poderão ser aprofundados com o auxílio do professor ou do monitor (FREITAS, 2015).

As Visitas e Viagens de Estudos são momentos em que os estudantes participam de experiências fora do ambiente escolar, que proporcionam reflexões e discussões em torno de um tema proposto no Plano de Estudo. Tais visitas podem proporcionar-lhes "descobertas de realizações, de empreendimentos, de organismos, de serviços, de lugares... e oportunidades de encontro com seus atores..." (GIMONET, 2007, p. 47).

Sendo assim, os intrumentos pedagógicos da PA podem favorecer uma participação ativa do estudante, colocando-o na função de sujeito de sua própria aprendizagem. A articulação da vida do estudante com a escola e com os conhecimentos científicos é fundamental para o desenvolvimento e a consolidação desses instrumentos. É nesse contexto de relação e formação que a PA se constitui como uma alternativa de formação dos estudantes, seja em que contexto for. Os estudantes têm a oportunidade de (re)construir novas aprendizagens a partir do contexto em que estão inseridos.

\section{A Metodologia da Resolução de Problemas}

A RP como teoria surgiu em meados do século $X X$, nos Estados Unidos, contrapondo-se às práticas habituais de exercícios de repetição. Nesses exercícios é comum o professor fornecer à criança a forma de resposta que ele quer que a criança encontre, sem levar muito em consideração o pensamento e o raciocínio do indivíduo. De forma reativa a essa perspectiva de trabalho é que a RP foi se constituindo com uma teoria, com as contribuições do matemático e pesquisador George Polya, principalmente com uma das suas principais produções, um clássico na literatura mundial, $A$ arte de resolver problemas ${ }^{3}$ (ANDREATTA; ALLEVATO, 2018). Nesse livro, Polya (1945) apresenta quatro

\footnotetext{
3 O livro de Polya (1945) destaca uma preocupação com a melhoria das habilidades da Resolução de Problemas pelos estudantes e com a necessidade de os professores se tornarem bons resolvedores de problemas, para, assim, fazerem de seus alunos também bons resolvedores de problemas.
} 
etapas $^{4}$ do pensamento no processo de resolução de problemas: (i) compreensão do problema; (ii) elaboração de um plano; (iii) execução do plano; (iv) retrospecto.

No âmbito internacional outros pesquisadores propagaram a teoria de Polya, no intuito de explorar a RP no ensino de Matemática. Podemos destacar as contribuições de Kilpatrick (1987), Krulik e Reis (1997), Schoenfeld (1992, 2007), Van de Walle (2009), dentre outros.

A utilização da RP como metodologia de ensino para a aprendizagem de conteúdos e conceitos matemáticos foi estimulada, no cenário internacional, pelo National Council of Teachers of Mathematics - NCTM dos Estados Unidos, que contribuiu com uma série de recomendações/orientações para o trabalho do professor, com novas tendências que poderiam levar a melhores possibilidades de ensinar e aprender matemática.

De modo especial o NCTM produziu os Standards (NCTM, 2000), estabelecendo princípios e padrões de conteúdo e de processos que descrevem o conteúdo a ser trabalhado e a forma como os alunos devem aprender. Em se tratando dos padrões, Andreatta e Allevato (2018) destacam que o primeiro padrão de processo indicado pelos Standards foi a Resolução de Problemas, sugerindo-a como uma abordagem/metodologia para o trabalho em sala de aula.

As pesquisadoras brasileiras Onuchic e Allevato (2011) ressaltam que foi a partir dos Standards (NCTM, 2000) que os professores de matemática passaram a pensar na RP como uma metodologia de ensino possível para a aprendizagem de conteúdos e conceitos matemáticos. Elas acreditam que o ensino e a aprendizagem de Matemática através da Resolução de Problemas sugerem que o problema proposto aos estudantes possibilite a utilização de seus conhecimentos prévios, de modo que sejam capazes de escolher a melhor estratégia a ser utilizada para encontrar a solução e, assim, discutir e validar suas respostas e aprender matemática.

No Brasil, acompanhando as recomendações dos Standards (NCTM, 2000), tivemos a implantação dos Parâmetros Curriculares Nacional - PCN,

\footnotetext{
4 A pesquisa de Valerio (2017), disponível no link: http://www.teses.usp.br/teses/disponiveis/55/55136/tde-06032017-101943/pt-br.php, apresenta uma discussão acerca das etapas para Resolução de Problemas propostas por Polya (1945).
} 
organizados em ciclos com dois volumes para o ensino fundamental (BRASIL, 1997, 1998) e um para o ensino médio (BRASIL, 1999). Esses documentos apontam a RP como um ponto de partida das atividades em Matemática, de forma que os estudantes possam levantar ideias matemáticas, estabelecer relações entre elas, desenvolver formas de raciocínio, estabelecer conexões entre temas matemáticos e de fora da matemática, desenvolver a capacidade de resolver problemas, dentre outros (ANDREATTA; ALLEVATO, 2018).

Concordamos com as orientações dos PCN quando destacam alguns princípios para o trabalho com a RP em sala de aula. São eles:

\begin{abstract}
A situação-problema é o ponto de partida da atividade matemática e não a definição. No processo de ensino e aprendizagem, conceitos, ideias e métodos matemáticos devem ser abordados mediante a exploração de problemas, de forma que os alunos desenvolvam algum tipo de estratégia para resolvê-las; A resolução de problemas não é uma atividade para ser desenvolvida em paralelo ou como aplicação da aprendizagem, mas uma orientação para a aprendizagem, pois proporciona o contexto em que se pode aprender conceitos, procedimentos e atitudes matemáticas. (BRASIL, 1998, p. 41)
\end{abstract}

Com efeito, percebemos que o trabalho com a RP pode possibilitar aos estudantes a mobilização de conhecimentos e 0 desenvolvimento das habilidades de gerenciar as informações que estão a sua disposição. "Ainda [...] os alunos terão oportunidade de ampliar seus conhecimentos acerca de conceitos e procedimentos matemáticos, bem como de ampliar a visão que têm dos problemas, da Matemática, do mundo em geral e desenvolver sua autoconfiança" (BRASIL, 1998, p. 40).

Ao direcionarmos o olhar para a abordagem com a RP na Base Nacional Comum Curricular - BNCC (BRASIL, 2017), percebemos que aparece o termo "resolver problemas" na competência geral, direcionado à ideia de "preparar" o aluno para resolver problemas diante de situações e contextos das ciências. Nas competências específicas, o trabalho com a RP está voltado para uma perspectiva de aprender matemática para depois resolver problemas, e não resolver problemas para aprender matemática (ANDREATTA; ALLEVATO, 2018). 
A afirmação a seguir, transcrita da BNCC, confirma tal perspectiva mencionada no final do parágrafo anterior.

[...] assim, espera-se que eles desenvolvam a capacidade de identificar oportunidades de utilização da matemática para resolver problemas, aplicando conceitos, procedimentos e resultados para obter soluções e interpretá-las segundo os contextos das situações. (BRASIL, 2017, p. 263)

Entretanto, identificamos também referências de abordagem com a RP como metodologia/recurso para a aprendizagem de conteúdos e conceitos matemáticos:

Os processos matemáticos de resolução de problemas, de investigação, de desenvolvimento de projetos e da modelagem podem ser citados como formas privilegiadas da atividade matemática, motivo pelo qual são, ao mesmo tempo, objeto e estratégia para a aprendizagem ao longo de todo o Ensino Fundamental. (BRASIL, 2017, p. 264)

Contrapondo-se a perspectiva de trabalho em que primeiro se aprendem conteúdos matemáticos para depois resolver problemas é que propomos discussões neste artigo, entendendo que a RP é um recurso, uma metodologia, e a partir dela podemos aprender conteúdos e conceitos matemáticos, também na Educação do Campo.

O exemplo de uma prática pedagógica envolvendo a RP na Educação do Campo que apresentaremos na próxima seção está direcionado para a perspectiva metodológica das pesquisadoras Allevato e Onuchic (2014), que exploram o ensino de Matemática através da Resolução de Problemas não só com o objetivo de aprender matemática, mas também com o intuito de fazer matemática. Nesse contexto, propõem a perspectiva metodológica de EnsinoAprendizagem-Avaliação de Matemática através da Resolução de Problemas. Essa ampliação se concretiza em um roteiro com dez etapas propostas por elas para a formalização de conteúdos matemáticos através de RP, conforme quadro 01. 
Quadro 01 - Roteiro da Metodologia de Ensino-Aprendizagem-Avaliação de Matemática através da Resolução de Problemas

\begin{tabular}{|c|c|}
\hline Etapa & Detalhamento \\
\hline 1. Proposição do problema & $\begin{array}{l}\text { O professor escolhe o problema e organiza } \\
\text { as tarefas }\end{array}$ \\
\hline 2. Leitura individual & $\begin{array}{l}\text { Uma cópia do problema é entregue ao } \\
\text { estudante e esse faz a leitura individual. }\end{array}$ \\
\hline 3. Leitura em conjunto & $\begin{array}{l}\text { Em pequenos grupos os estudantes releem, } \\
\text { discutem e interpretam o problema. O } \\
\text { professor pode esclarecer eventuais dúvidas } \\
\text { do que se pede no problema. }\end{array}$ \\
\hline 4. Resolução do Problema & $\begin{array}{l}\text { Os estudantes utilizam seus conhecimentos } \\
\text { anteriores na busca pela solução. }\end{array}$ \\
\hline 5. Observar e incentivar & $\begin{array}{l}\text { O professor acompanha e monitora o } \\
\text { processo de resolução do problema } \\
\text { intervindo e estimulando o desenvolvimento } \\
\text { do trabalho. }\end{array}$ \\
\hline $\begin{array}{l}\text { 6. Registro das resoluções na } \\
\text { lousa }\end{array}$ & $\begin{array}{l}\text { Representantes dos grupos de estudantes } \\
\text { são convidados a registrar, na lousa, suas } \\
\text { resoluções. Resoluções certas, erradas ou } \\
\text { feitas por diferentes processos devem ser } \\
\text { apresentadas para que os estudantes as } \\
\text { analisem e discutam. }\end{array}$ \\
\hline 7. Plenária & $\begin{array}{l}\text { Em plenária discute-se e argumenta-se de } \\
\text { forma coletiva as resoluções apresentadas. } \\
\text { O professor atua como mediador das } \\
\text { discussões, incentivando a participação ativa } \\
\text { e efetiva de todos os estudantes. }\end{array}$ \\
\hline 8. Busca do consenso & $\begin{array}{l}\text { A partir das discussões em conjunto busca- } \\
\text { se chegar à conclusão sobre os resultados } \\
\text { corretos. }\end{array}$ \\
\hline 9. Formalização do conteúdo & $\begin{array}{lllr}\text { O professor formaliza } & \text { o } & \text { conteúdo, } \\
\text { apresentando } & \begin{array}{l}\text { linguagem } \\
\text { matemática adequadas. }\end{array} & \text { e } & \\
\text { notação }\end{array}$ \\
\hline $\begin{array}{l}\text { 10. Proposição e resolução de } \\
\text { novos problemas }\end{array}$ & $\begin{array}{l}\text { Poderão ser propostos novos problemas a } \\
\text { fim de consolidar as aprendizagens } \\
\text { construídas nas etapas anteriores, assim } \\
\text { como aprofundar as compreensões acerca } \\
\text { do conteúdo/conceito matemático. }\end{array}$ \\
\hline
\end{tabular}

Fonte: adaptado de (ALLEVATO, 2014; ALLEVATO; ONUCHIC, 2014).

As autoras destacam que os problemas, ao serem propostos aos alunos, precisam possibilitar que utilizem seus conhecimentos prévios, de modo que sejam capazes de escolher a melhor estratégia para encontrar a solução e, assim, discutir, refletir e validar suas respostas e aprender matemática. Um bom 
problema é, então, aquele que aguça o trabalho mental de forma prazerosa durante a investigação e a descoberta da resolução; promove a criatividade; e aprimora o raciocínio (ALLEVATO; ONUCHIC, 2014).

Prática Pedagógica ${ }^{5}$ envolvendo a Metodologia da Resolução de Problemas na Educação do Campo

O ensino da Matemática na Educação do Campo, principalmente nos anos iniciais do Ensino Fundamental, pode ser explorado através da Resolução de Problemas. A RP pode ser também um recurso em favor da aprendizagem de conteúdos e conceitos matemáticos com estudantes em um contexto da Educação do Campo.

Nessa perspectiva, a utilização da RP torna-se possível e viável nos anos iniciais do Ensino Fundamental de uma Escola Comunitária Rural localizada em Colatina, estado do Espírito Santo A prática pedagógica apresentada a seguir evidencia essa possibilidade. Apresentamos a resolução de um problema gerador envolvendo a metodologia de Ensino-Aprendizagem-Avaliação de Matemática através da Resolução de Problemas com estudantes do $5^{\circ}$ ano do Ensino Fundamental seguindo o roteiro metodológico apresentado no quadro 01.

O problema que apresentamos esteve relacionado ao tema gerador Terra, envolvendo medidas de massa, conforme apresentado no quadro 02.

\section{Quadro 02 - Problema das Sacas de Café}

No final da colheita de café o Senhor Alfredo conseguiu colher 55 sacas de café de $60 \mathrm{~kg}$ cada saca e precisa guardar o café no Armazém da Cooabriel em São Gabriel da Palha. Alfredo alugou um caminhão que suporta até 3 toneladas de peso e não sabe se poderá transportar todo o café que produziu de uma só vez. Alfredo sem saber o que fazer foi até a Escola Padre Fulgêncio e pediu aos estudantes do $5^{\circ}$ Ano para ajudálo a descobrir se o café poderá ser transportado em uma única viagem, para não pagar muito frete. E agora? Como podemos ajudar o Senhor Alfredo?

Fonte: (ANDREATTA, 2020)

Levando em consideração as etapas da metodologia de EnsinoAprendizagem-Avaliação de Matemática através da Resolução de Problemas

\footnotetext{
${ }^{5} \mathrm{~A}$ prática relatada neste trabalho faz parte de uma pesquisa maior de doutorado (ANDREATTA, 2020), defendida em junho na Universidade Cruzeiro do Sul - Unicsul/SP, aprovada pela Comitê de Ética com parecer número 2.439.347 - Plataforma Brasil.
} 
(ALLEVATO; ONUCHIC, 2014), iniciamos o processo de desenvolvimento do problema em um cenário de ação-reflexão-ação conjunta entre professor pesquisador, professor regente e estudantes, que conduziram esses momentos da pesquisa. Esse cenário foi se constituindo no desenvolvimento das etapas da metodologia, proporcionando liberdade e autonomia aos estudantes na construção das ideias e argumentações, de modo que agimos como mediadores e incentivadores em busca da solução do problema.

$\mathrm{Na}$ primeira etapa do processo, o professor pesquisador fez considerações junto aos estudantes sobre o contexto do problema, apresentando-o a eles e propondo análises iniciais e resoluções individuais. $\mathrm{Na}$ segunda etapa os professores pesquisador e regente acompanharam a leitura individual e silenciosa do problema. Após esse momento, um estudante pediu para ler em voz alta. Isto feito, a professora regente desafiou os estudantes a utilizarem os conhecimentos que já possuíam sobre medidas de massa, principalmente em relação à unidade de tonelada.

No terceiro momento/etapa, os professores envolvidos observaram as primeiras tentativas individuais de resolução do problema. Depois, em trios os estudantes começaram a discutir as primeiras resoluções e pensamentos que desenvolveram. Alguns queriam apagar o que haviam feito ao verem a resolução do colega. Então o professor pesquisador valorizou a resolução de cada estudante destacando que todas eram importantes, de forma que não se preocupassem naquela fase com resoluções certas ou erradas. Mas, ainda assim, alguns estudantes apagaram o que haviam desenvolvido.

$\mathrm{Na}$ quarta e quinta etapas, com a observação das resoluções, individuais e coletivas, percebemos que a maior parte dos estudantes conseguiu realizar o algoritmo inicial da multiplicação da quantidade de sacas de café pelo peso de cada saca. É curioso destacar que alguns estudantes, ao encontrarem a quantidade de café produzida pelo Senhor Alfredo, multiplicaram o resultado por três, referindo-se às 3 toneladas de limite do peso do caminhão, conforme a figura 1, a seguir: 


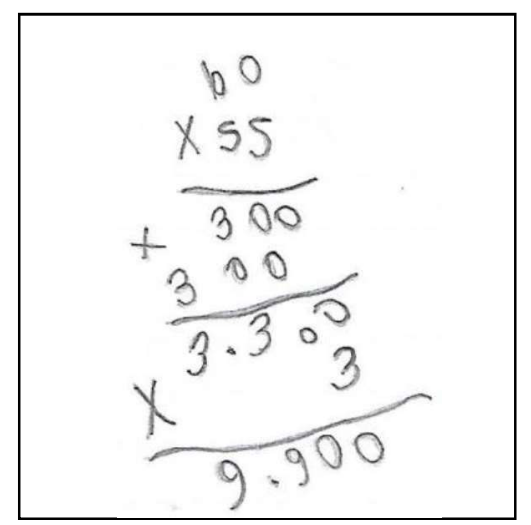

Figura 1 - Resolução do problema das Sacas de Café

Fonte: (ANDREATTA, 2020)

Essa resolução sugere fragilidades na compreensão do problema e nas inferências acerca das informações fornecidas. Alguns estudantes vão realizando os cálculos com as informações trazidas pelo problema sem parar para refletir qual é o sentido do que está fazendo, ou sem estabelecer estratégias para a resolução.

Nesse sentido, percebemos que a metodologia de resolução de problemas aqui proposta pode minimizar a ocorrência de situações apresentadas no parágrafo anterior quando os estudantes têm a possibilidade de discutir, refletir e apresentar o que fizeram. O momento de discussão das resoluções em plenária, que corresponde às etapas seis e sete, é importante, pois o diálogo, a troca de ideias e discussão das concepções permitem reflexões e percepções que, possivelmente, em um ambiente de aprendizagem individual não ocorra. Nesse cenário o ensino é realizado através de parcerias entre professor pesquisador, professor regente e alunos, pois os estudantes têm liberdade para questionar, e em conjunto com o professor vão refletir e buscar o conhecimento, respeitando as singularidades e multiplicidades da sala de aula (LEAL JUNIOR; ALLEVATO, 2018).

Essas reflexões foram desencadeadas, nessa etapa, quando um representante de cada grupo apresentou as resoluções do problema na lousa. De uma maneira geral, a maioria dos estudantes conseguiu calcular corretamente a quantidade total de café produzida pelo Senhor Alfredo, porém divergiram as respostas dadas pelos estudantes às perguntas propostas no problema. Alguns foram bem gerais na resposta, destacando que era necessária a realização de duas viagens com o caminhão para transportar o café até o 
armazém. Outros foram mais específicos e explicitaram a quantidade de peso em quilogramas e em sacas de café que poderia ser transportada em cada viagem. Um estudante preferiu dividir a quantidade de peso total das sacas de café pela metade, fazendo um "balanceamento" de peso entre as viagens, conforme presenciamos na figura 2 :

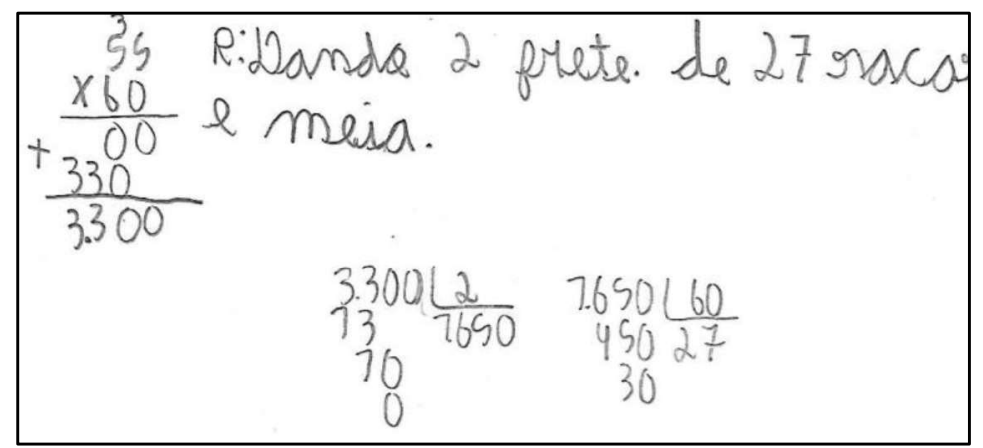

Figura 2 - Resolução do problema das Sacas de Café Fonte: (ANDREATTA, 2020)

É importante destacar que na etapa de escolarização dessa turma percebemos ainda a necessidade de representação ilustrativa e pictórica das situações, assim como a utilização de materiais concretos, o que também pode ser explorado em outras etapas de escolarização da Educação Básica. A utilização de estratégias como o desenho de figuras e representação de imagens pode ajudar a melhorar diversos processos envolvidos no pensamento matemático. Proença (2018) aponta que o estudante ao vivenciar a busca por padrões tendo a chance de supor, testar e desenhar pode melhorar a habilidade de formular hipóteses. Também Smole (1996) destaca a importância da utilização de símbolos no processo de aprendizagem da matemática, o que é possível no processo de aprendizagem com a RP, e propõe:

[...] relacionar o matemático e o pictórico através do desenho, como uma forma de comunicação, como uma parte importante da percepção espacial, como uma possibilidade de a criança iniciar a construção de uma significação para as diferentes representações com as quais terá contato ao longo da escolaridade, inclusive aquelas relacionadas à matemática [...] (SMOLE, 1996, p. 87).

Em plenária, nas sétima e oitava etapas, os professores pesquisador e regente e os estudantes discutiram as diversas formas de resolução e respostas 
obtidas pelos estudantes, a fim de chegarem a um consenso sobre a melhor ajuda possível ao Senhor Alfredo. Diante das resoluções apresentadas na lousa, os professores ratificaram a necessidade do Senhor Alfredo receber a orientação da melhor forma possível e correta. Como a maior parte das resoluções apresentou a quantidade total de café produzida pelo Senhor Alfredo, sendo que a maior dificuldade foi identificar a quantidade de toneladas que representasse tal valor, foi necessário retomar na lousa as convenções das unidades de massa.

Após as reflexões e a compreensão acerca das convenções das unidades de massa, os estudantes que ainda não tinham percebido a quantidade de toneladas de café produzidas, perceberam que ela não podia ser transportada em uma única viagem pelo caminhão. De modo especial, um estudante defendeu que o café poderia ser levado em uma única viagem, justificando que o peso excedente a 03 toneladas era uma quantidade pequena. Nesse momento a professora regente destacou que o proprietário do caminhão poderia ser multado caso ultrapasse o limite de peso do caminhão, e que essa não era a informação correta a ser direcionada ao Senhor Alfredo.

A professora regente finalizou a discussão ressaltando que o problema proposto apresenta diversas possibilidades de respostas que poderão ser encaminhadas ao Senhor Alfredo, desde que o limite de peso do caminhão seja respeitado. Alguns estudantes sentiram-se tão importantes em poder ajudar o Senhor Alfredo que chegaram a perguntar se ele teria vindo mesmo à escola solicitar ajuda.

Esse protagonismo dos estudantes é significativo e constitui a base da Pedagogia da Alternância, no sentido de que o modo de vida e a cultura dos estudantes é tão formativo quanto às aulas. Freire (1983) destaca que um dos papéis da Educação está em problematizar com o(a)s educando(a)s a realidade que os mediatiza e não discorrer de maneira autoritária e assistencialista sobre ela, como se essa realidade fosse pronta e acabada.

Os estudos de D'Ambrósio (2005) também evidenciam a necessidade de valorizar a cultura na qual os estudantes estão inseridos, preparando-os para uma participação mais efetiva na comunidade. 
Na décima e última etapa, após a formalização dos conteúdos propostos, o professor pesquisador pensou em uma outra situação e propôs um novo problema aos estudantes, tendo em vista a informação encaminhada pela professora regente de que cada saca de café custa em média, na região, $R \$$ 306,00 (trezentos e seis reais). A professora regente incentivou os estudantes a descobrirem qual o valor em dinheiro que o Senhor Alfredo poderia faturar com a venda do café. Se esse valor é muito ou pouco. Incentivou, ainda, os estudantes a pesquisarem em casa, com os familiares ou vizinhos, quais despesas são necessárias para a produção do café e que precisam ser descontadas após a venda do mesmo. A professora regente ficou de retornar essa discussão com os estudantes no dia seguinte, após o retorno das pesquisas que realizariam em casa.

\section{Considerações Finais}

Ao propormos neste artigo discussões históricas e teóricas da RP e da modalidade de ensino - Educação do Campo, assim como uma prática pedagógica envolvendo a metodologia da Resolução de Problemas em uma turma dos anos iniciais do Ensino Fundamental de uma EMCORR, percebemos a importância da conexão entre essa modalidade de ensino e a metodologia RP, pois a prática pedagógica demonstrada proporcionou aos estudantes momentos de interação, discussão, diálogo, autonomia e argumentação em diferentes contextos de aprendizagem envolvendo conteúdo matemático.

Na metodologia da RP, assim como em outras, o papel do professor é fundamental, tendo em vista que todo o trabalho precisa estar alicerçado nas relações que se estabelecem em sala de aula e no conhecimento que o docente tem dos estudantes. Na Educação do Campo da mesma forma que em outras modalidades de ensino da Educação Básica, cada estudante possui suas características e singularidades no processo de ensino e aprendizagem em sala de aula e aprende de forma diferente os conhecimentos e os conteúdos que o professor pretende alcançar.

Constamos que a forma de organização didático-pedagógica em Pedagogia da Alternância da EMCOR participante da pesquisa, permitiu que 
articulássemos a Resolução de Problemas com o contexto de vida dos estudantes favorecendo uma aprendizagem mais autônoma e dialógica.

Nos anos iniciais do Ensino Fundamental, assim como em outras etapas da Educação Básica e no Ensino Superior, é importante que o professor os motive a participar das resoluções dos problemas e a entender os conceitos ali contidos. Os estudantes precisam do fator motivacional para interessar-se pelo problema (ONUCHIC; ALLEVATO, 2011). De acordo com Leal Junior e Allevato (2018), muitos pesquisadores defendem a abordagem de ensino com a Resolução de Problemas como a mais indicada para a construção de conhecimento matemático, visto que ela coloca o aluno como principal responsável pela construção de seu conhecimento.

Sendo assim, acreditamos que a metodologia apresentada neste artigo pode ser indicada para a aprendizagem de conteúdos e conceitos matemáticos na Educação do Campo, principalmente nos primeiros anos de escolarização. Quando proporcionamos ambientes de aprendizagem mais próximos à realidade e ao contexto dos estudantes, percebemos um envolvimento mais favorável e propício à aprendizagem, principalmente quando há diálogos, troca de ideias, argumentações e discussões, o que foi possível identificar na prática pedagógica apresentada neste trabalho.

\section{Referências}

ALLEVATO, N. S. G. Ensino-Aprendizagem-Avaliação de Matemática: por que através da resolução de problemas: In: Seminário em Resolução de Problemas, 3. APRESENTAÇÃO EM MESA REDONDA. 2014, Rio Claro.

ALLEVATO, N. S. G; ONUCHIC, L. R. Ensino-aprendizagem-avaliação de Matemática: por que através da resolução de problemas. In: ONUCHIC, L. R. et al. (Org.). Resolução de problemas: teoria e prática. Jundiaí: Paco, 2014.

ANDREATTA, C. Aprendizagem Matemática através da Elaboração e Resolução de Problemas em uma Escola Comunitária Rural. 2020. $203 f$. Tese (Doutorado em Ensino de Ciências e Matemática) - Programa de PósGraduação em Ensino de Ciências e Matemática, Universidade Cruzeiro do Sul, São Paulo, 2020.

ANDREATTA, C. Ensino e Aprendizagem de Matemática e Educação do Campo: O caso da Escola Municipal Comunitária Rural "Padre Fulgêncio do Menino Jesus", Município de Colatina, Estado do Espírito Santo. 2013.155f. 
Dissertação (Mestrado em Educação em Ciências e Matemática) - Instituto Federal do Espírito Santo, Vitória, 2013.

ANDREATTA, C.; ALLEVATO, N. S. G. A resolução de problemas nos documentos de orientação curricular oficiais da Educação Básica Brasileira. In: SEMINÁRIO INTERNACIONAL DE PESQUISA EM EDUCAÇÃO MATEMÁTICA, 07.., 2018. Foz do Iguaçu, PR. Anais eletrônicos... Foz do Iguaçu: Sociedade Brasileira de Educação Matemática, SBEM, 2018. p.1-12. Disponível

em: http://www.sbemparana.com.br/eventos/index.php/SIPEM/VII_SIPEM/paper/vie w/466/498. Acesso em: 09 abr. 2019.

BRASIL. Lei 9.394, de 20 de dezembro de 1996. Lei de Diretrizes e Bases da Educação Nacional. Brasília-DF, 1996.

BRASIL. Ministério da Educação (MEC). Parâmetros Curriculares Nacionais: Matemática - $1 .^{\circ}$ e $2 .^{\circ}$ ciclos. Brasília: MEC, 1997.

BRASIL. Ministério da Educação (MEC). Parâmetros Curriculares Nacionais: Matemática - 3. ${ }^{\circ}$ e $4 .^{\circ}$ ciclos. Brasília: MEC, 1998.

BRASIL. Ministério da Educação (MEC). Parâmetros Curriculares Nacionais: Matemática - Ensino Médio. Brasília, MEC, 1999.

BRASIL. Resolução CNE/CEB n. ${ }^{\circ}$ 1, de 03 de abril de 2002 - Diretrizes Operacionais para a Educação Básica nas Escolas do Campo. Brasília: MEC/CNE/CEB, 2002.

BRASIL. Parecer CNE/CEB n. ${ }^{\circ}$ 1, de 01 de fevereiro de 2006 - Dias letivos para a aplicação da Pedagogia de Alternância nos Centros Familiares de Formação por Alternância (CEFFA). Brasília: MEC/CNE/CEB, 2006.

BRASIL. Resolução CNE/CEB n. 4, de 13 de julho de 2010 - Diretrizes Curriculares Nacionais Gerais para a Educação Básica. Brasília: MEC/CNE/CEB, 2010.

BRASIL. Conselho Nacional de Educação. Resolução 2/2017. Institui e orienta a implantação da Base Nacional Comum Curricular. Brasília, 2017.

COLATINA. Lei $n^{\circ}$ 5.734, de 29 de junho de 2011. Altera denominação da Escola Municipal de Ensino Fundamental "Padre Fulgêncio do Menino Jesus". Colatina: Secretaria Municipal de Educação. Disponível em: http://legislacaocompilada.com.br/colatina/norma.aspx?id=2348\&tipo=1\&numer o=5734\&ano=2011. Acesso em: 15 out. 2018.

COLATINA. Lei $\mathbf{n}^{\circ} \mathbf{5 . 8 6 4}$, de 10 de julho de 2012. Institui a Educação do Campo no município de Colatina. Colatina, ES, 2012.

COLATINA. Lei $\mathbf{n}^{\circ}$ 6.362, de 3 de novembro de 2016. Regulamenta a Lei Municipal $n^{\circ}$ 5.864, de 10 de julho de 2012, que institui a Educação do Campo no município de Colatina. Colatina, ES, 2016. Disponível em: 
https://leismunicipais.com.br/ES/COLATINA/LEI-6362-2016-COLATINA-ES.pdf. Acesso em: 21 ago. 2019.

D'AMBROSIO, U. Etnomatemática: elo entre as tradições e a modernidade. 2. ed. $2^{\mathrm{a}}$ reimp, Belo Horizonte: Autêntica, 2005.

FREIRE, P. Educação como prática de liberdade. Rio de Janeiro: Paz e Terra, 1981.

FREIRE, P. Extensão ou comunicação. Rio de Janeiro: Paz e Terra, 1983.

FREITAS, G. V. Formação em Pedagogia da Alternância: um estudo sobre os processos formativos pela AMEFA junto aos monitores das EFAs do meio Jequitinhonha - MG. 253f. Dissertação (Mestrado Profissional em Educação do Campo) - Programa de Pós-Graduação em Educação do Campo. Universidade Federal do Recôncavo da Bahia, Amargosa, 2015.

GIMONET, J. C. Praticar e compreender a Pedagogia da Alternância dos CEFFA's. Coleção AIDEFA, São Paulo: Vozes, 2007.

KILPATRICK, J. Problem formulating: where do good problems come from? In: SCHOENFELD, A. H. Cognitive science and mathematics education. Hillsdale, New Jersey: Erlbaum, 1987, p. 123-147.

KRULIK, S.; REYS, R. E. A resolução de problemas na matemática escolar. Tradução de Hygino H. Domingues e Olga Corbo. São Paulo: Atual, 1997.

LEAL JUNIOR, L. C.; ALLEVATO, N. S. G. Momento pedagógico e pedagogia da pergunta: deslocamento conceitual para a prática em resolução de problemas. In: PINHEIRO, J. M. L.; LEAL JUNIOR, L. C. (Orgs.). A matemática e seu ensino: olhares em educação matemática. São Paulo: Livraria da Física, 2018.

NATIONAL COUNCIL OF TEACHERS OF MATHEMATICS. Principles and standards for school mathematics. Reston: NCTM, 2000.

ONUCHIC, L. R.; ALLEVATO, N. S. G. Pesquisa em resolução de problemas: caminhos, avanços e novas perspectivas. Boletim de Educação Matemática BOLEMA, Rio Claro, v. 25, n. 41, p. 73-98, dez. 2011.

POLYA, G. A arte de resolver problemas. Trad. e adapt. de Heitor Lisboa de Araújo. Rio de Janeiro: Interciência, 1978 [1945].

PROENÇA, M. C. Resolução de Problemas: encaminhamentos para o ensino e a aprendizagem de Matemática em sala de aula. Maringá: Eduem, 2018.

SCHOENFELD, A. H. Learning to think mathematically: Problem solving, metacognition, and sense making in mathematics. In: GROUWS, D. (Ed.). Handbook of research on mathematics teaching and learning. New York: McMillan, 1992. p. 334-370. 
SCHOENFELD, A. H. Problem solving in the United States, 1970-2008: research and theory, practice and politics. ZDN Mathematics Education, Karlsruhe, n. 39, p.537-551, 2007.

SMOLE, K. C. S. A matemática na educação infantil: a teoria das inteligências múltiplas na prática escolar. Porto Alegre: Artes Médicas, 1996.

TELAU, R. A importância do plano de estudo - a metodologia da Pedagogia da Alternância - na formação dos estudantes do $9^{\circ}$ ano da Escola Municipal Comunitária Rural Padre Fulgêncio do Menino Jesus. Projeto de Pesquisa e Experimentação Pedagógica (Especialização em Pedagogia da Alternância e Educação do Campo) - Universidade Federal de Minas Gerais, Belo Horizonte, 2012.

VALERIO, W. Resolução de problemas, uma abordagem com questões da OBMEP em sala de aula. 2017. 87f. Dissertação (Mestrado em Ciências) Programa de Pós-Graduação em Mestrado Profissional em Matemática em Rede Nacional, Instituto de Ciências Matemáticas e de Computação, Universidade de São Paulo, São Paulo, 2017.

VAN de WALLE, J. A. Matemática no Ensino Fundamental: formação de professores e aplicação em sala de aula. Tradução de Paulo Henrique Colonese. 6. ed. Porto Alegre: Artmed, 2009.

\section{Sobre os Autores}

\section{Cidimar Andreatta}

cidimarcol@gmail.com

Doutor em Ensino de Ciências e Matemática pela Universidade Cruzeiro do Sul (unicsul/SP).

Mestre em Educação, Ciências e Matemática pelo Instituto Federal do Espírito Santo (2013).

Professor Titular do curso de Pedagogia da Faculdade Pública de Ensino Superior de Linhares - Faceli

\section{Norma Suely Gomes Allevato}

normallev@gmail.com

Professora Doutura e Pesquisadora da Universidade Cruzeiro do Sul - SP.. 